\title{
Design and Application of Genetic Algorithm Based on Signal Game and Newsboy Model for Optimizing Supply Chain
}

\author{
Yue Zhao (iD, Yang Shen (D), and Jiaqi Yan \\ School of Journalism and Communication, Tsinghua University, Beijing 100084, China \\ Correspondence should be addressed to Yang Shen; yshen1974@mail.tsinghua.edu.cn
}

Received 2 July 2021; Revised 28 July 2021; Accepted 28 July 2021; Published 9 August 2021

Academic Editor: Daqing Gong

Copyright (c) 2021 Yue Zhao et al. This is an open access article distributed under the Creative Commons Attribution License, which permits unrestricted use, distribution, and reproduction in any medium, provided the original work is properly cited.

\begin{abstract}
Reasonable communication and cooperation between enterprises are helpful for the efficient operation of a supply chain. To explore the maximum utility of an entire supply chain, we propose a supplier-manufacturer-seller supply-chain game decisionmaking model. We use the model as the fitness function of a genetic algorithm that calculates the optimal solution and optimizes the total utility parameters. We analyze the theoretical and practical properties of the supply-chain optimization process and implement it in MATLAB, which provides quantitative support and useful references for making business decisions and optimally managing a supply chain.
\end{abstract}

\section{Introduction}

With the increasingly fierce competition in the global market, competition is no longer limited to enterprises but is increasingly between rival supply chains [1]. An efficient supply chain responds more quickly to market demand, gives wider visibility for production, plans orders better, reduces enterprise operating costs and risks, and avoids inefficient revenue and expenses $[2,3]$. Therefore, enterprises are concerned about improving the operating efficiency of their supply chain.

Scholars generally believe that improving supply-chain efficiency is mainly achieved through the competition and cooperation between upstream and downstream enterprises acting under the influence of market demand $[4,5]$. Game theory (including cooperative games and noncooperative games) is recognized as one of the best methods to study supply chains, especially the competition and cooperation between members of a supply chain [6,7] (e.g., the newsboy model, Stackelberg game model, bargaining model, or signal game model $[8,9])$. Roy et al. [10] established a function of expected average cost for supply chains to obtain the optimal order quantity for suppliers, manufacturers, and retailers by balancing the inventory cost and shortage cost in the framework of the newsboy model. Pakseresht et al. [11] put forward the optimized configuration of green supply chain by analyzing the Stackelberg game, which involves the optimal selection of suppliers, manufacturers, assembly plants, distribution centers, and retailers. Matsui [12] discussed the optimal time for a manufacturer to bargain with a retailer in a dual-channel supply chain composed of a manufacturer and a retailer. Shao et al. [13] established a supplier-selection model with an embedded game in which the firm signals its supplier choice through price based on two mechanisms: signaling and disclosure.

In addition, optimizing a supply chain is essentially an overall planning problem, so many scholars put forward optimal models with intelligent algorithms to solve it. For example, genetic algorithms (GAs) in supply-chain optimization are a hot research topic. Radhakrishnan et al. [14] used GAs to optimize supply-chain inventory with lead times and predicted the optimal stock levels to be maintained to minimize the total supply-chain cost. Istokovic et al. [15] presented a simulation-optimization approach that combines a discrete event simulation and a GA to solve the batching and batch scheduling problem in a hybrid flow shop. Pirnagh et al. [16] analyzed the bi-objective closedloop supply-chain problem with shortage and all unit discount; they use the nondominated sorting GA II and multiobjective particle swarm optimization to optimize the 
supply chain. In other works, Shi et al. [17] established a dynamic scheduling model for the flexible job-shop scheduling problem with fuzzy delivery time and then solved the model with an improved immune GA. The results shed light on the flexible job-shop scheduling problem in realworld scenarios. Finally, Amjad et al. [18] proposed a fourlayered GA and implemented it with adaptive parameters of population initialization and operator probabilities to intelligently manage intensification and diversification.

The existing literature shows that scholars have explored the fair and reasonable distribution of income between objects and the maximum incentive of the supply chain by building a mathematical model of the game, which provides a decision-making basis for balancing the income between supply chain objects and improving the overall efficiency of the supply chain. However, most of the research focuses on the optimization problems at one phase of the supply chain, such as production plan, inventory management, procurement decision-making, or pricing strategy, and lack of a more systematic analysis framework. In other words, the game relationship between members of the supply chain and the optimal decision-making need to be further explored from a systematic perspective. For supply-chain optimization, most scholars use intelligent algorithms (such as GAs or particle swarm optimization) to optimize the design from the perspective of overall planning, which provides ideas for studying the overall optimization of a supply chain. This paper studies supply-chain optimization from the perspective of agent behavior decision. The purpose of supplychain optimization is to find a decision-making scheme to promote coordination between members in the supply chain and achieve the maximum total utility under conditions of constraint or limited resources. With that in mind and based on the analysis of a typical supply-chain model, this paper proposes a GA optimization for a supply chain based on a signal game and the newsboy model by combining the game model and intelligent algorithms. We also iterate the GA through numerical simulation to implement the optimaldecision solution for the agent to maximize supply-chain utility.

\section{Building the Model and Designing the Algorithm}

2.1. Analysis of Typical Supply-Chain Mode. Depending on the objectives of supply-chain management, a supply chain can be divided into three modes: a supply chain oriented by manufacturers, a supply chain oriented by retailers (supermarket chain), and a logistics service supply chain oriented by 3PL (an integrated logistics supplier). This paper argues that the supply chain oriented by manufacturers is a whole functional network in which manufacturers are the core enterprises in the supply chain, which can attract related firms to join the chain and connect suppliers, manufacturers, sellers, and users. Under the background of "Made in China 2025" and unlike the supply chain with suppliers or sellers as the core, the supply chain oriented by manufacturing firms has purchasing, manufacturing, and sales functions, which are more representative and typical.
Therefore, this paper takes the supply chain oriented by manufacturing firms as the research object for supply-chain optimization.

The term "manufacturing firms" refers to the manufacturers who directly produce the final products for the end consumer. The end consumer can be either the user of capital goods or the user of laboring materials as a means of production. The final product can be both the production goods and the labor data in the means of production. The upstream firms that provide raw materials or parts to manufacturing firms belong to the category of suppliers because their products (such as raw materials or parts) are the subject of labor of manufacturing firms and are, by nature, intermediate goods. Downstream of a supply chain are found mainly distributors and retailers responsible for the final product sales and provide after-sales services, belonging to the category of distributors. To sum up, the typical supply-chain mode studied in this paper is shown in Figure 1 . The characteristic of this mode is that the "chain master" in the supply chain is the manufacturer. Different from the general node firms, the manufacturers not only form the bridge between suppliers and sellers but also direct, guide, and coordinate the relationship between other node firms so as to coordinate the development of firms in the chain.

\subsection{Construction of Game Decision-Making Model for Supply Chain}

2.2.1. The Signal Game Model between Supplier and Manufacturer. Signal games involve two participants: the signal sender, who sends out private information, and the signal receiver, who makes decisions based on the information from the sender [19]. Most of the transactions between upstream suppliers and midstream manufacturers occur in an environment of incomplete information, which is modeled as a signal game under incomplete information. From the perspective of the whole process of a transaction between raw materials, parts suppliers, and product manufacturers, a series of activities such as obtaining transaction information, determining transaction contracts, and performing and supervising all consume resources. However, to ensure the smooth progress of the transaction, the resources initially used must produce products for the transaction to achieve the purpose of the transaction. The transaction process between suppliers and manufacturers is a bargaining game based on the interests of both parties to make an acceptable transaction price. The signal game model of the supplier and manufacturer is to construct the utility function of both sides under certain constraints. In this paper, the whole signal transmission process between the supplier and manufacturer is divided into two stages (namely, the preparation period and transaction period), and the following assumptions are put forward before the game analysis:

H1: in the preparation period, the supplier and the manufacturer are assumed to send signals and play a game at the same time without knowing each other's 


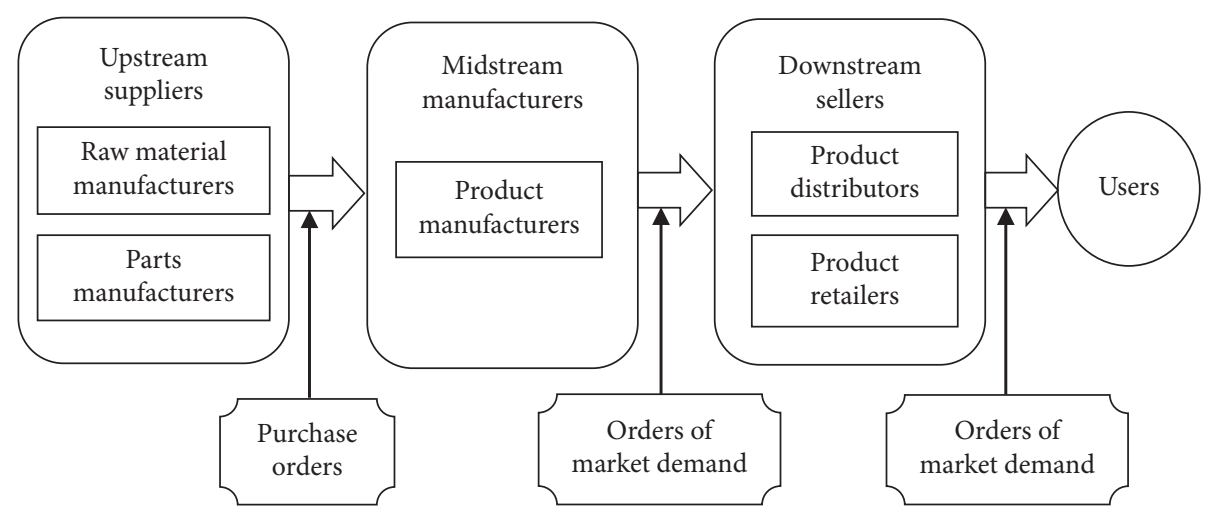

Figure 1: Supply chain mode oriented by manufacturing firms.

type. Both parties in the game are signal senders and signal receivers. The behavior of suppliers and manufacturers (advertising investment behavior and consulting investment behavior) can reflect and transmit information.

$\mathrm{H} 2$ : in the transaction period, the decision-making of suppliers and manufacturers is assumed to be affected by the signals of the preparation period, and the repeated game of bargaining is assumed to be carried out based on transaction intention.

Based on these assumptions, the two-stage signaling game between the supplier and manufacturer proceeds as follows: (1) in the preparation period, the signal sent by the supplier to the manufacturer is the level of investment in advertising, $a_{1}\left(a_{1} \in[0,1]\right)$, and the signal sent by the manufacturer to the supplier is the level of investment in consultation, $b_{2}\left(b_{2} \in[0,1]\right)$. (2) During the transaction period, the signal sent by the supplier to the manufacturer is the price of raw materials and parts, $p_{1}$, and the signal sent by the manufacturer to the supplier is the purchase quantity of raw materials and parts, $q_{2}$. The type of supplier is measured by enterprise quality $\eta(\eta \in[0,1])$, which is a concept of supply capability, raw material supply, and parts quality. The type of manufacturer is measured by its demand for raw materials and parts, $\varepsilon(\varepsilon \in[0,1])$, which is determined by its production capacity and market demand.

The utility function of the supplier is

$$
U_{1}\left(a_{1}, p_{1}, b_{2}, q_{2}\right)=p_{1} q_{2}-\frac{1}{2} \mu^{-1} a_{1}^{\eta}+b_{2} \varepsilon
$$

The utility function of the manufacturer is

$$
U_{2}\left(a_{1}, p_{1}, b_{2}, q_{2}\right)=q_{2} \eta+a_{1} \varepsilon b_{2}-b_{2}-p_{1} q_{2}-\left(\varepsilon-q_{2}\right)^{2} .
$$

The quantity $(1 / 2) \mu^{-1} a_{1}^{\eta}$ is the advertising cost of different quality types of raw materials and parts suppliers in the same level of advertising investment, where $\mu$ is the perceived coefficient of advertising investment. The product $q_{2} \eta$ refers to the actual usage or perceived benefits of the type- $\varepsilon$ manufacturer when the quantity of raw materials and parts is $q_{2}$ (raw materials and parts products are supplied by type- $\eta$ supplier). The quantity $\left(\varepsilon-q_{2}\right)^{2}$ refers to the use loss due to shortage or surplus of the type- $\varepsilon$ manufacturer when the manufacturer's purchase quantity of raw materials and parts is $q_{2}$. To fully explain the influence of these four signals, this paper does not consider how other factors in the market affect the utility function of suppliers and manufacturers, such as the promotion of brand value brought by the increase of market share, the possible future benefits brought by the manufacturer's recommended value, or the opportunity cost that the manufacturer pays for its search in the preparation before the transaction.

\subsubsection{Newsboy Model of Seller's Optimal Decision under} Manufacturer's Lead. The newsboy model is a mathematical model in which the manager decides the optimal order quantity when facing a stochastic demand [20]. The model is simple, straightforward, and practical and has been widely used in the research of supply-chain management and optimization $[21,22]$. In the supplier-manufacturer-seller supply chain, the seller considers both cost and profit in the process of ordering products from the manufacturer [23]. The seller must balance the reduction of residual risk and the realization of revenue, then determine the seller's optimal order quantity, and price the product at the critical point. Therefore, the newsboy model is more appropriate to analyze the game between the manufacturer and seller. In a downstream supply chain with the manufacturer as lead, the seller can find the optimal order quantity and price according to the market demand. In other words, the goal of this part is to build the newsboy model for an optimal seller decision of sellers under the manufacturer's lead.

This paper assumes that the product's market demand is a random variable related to the product pricing, and the product manufacturer has unlimited capacity. In the face of stochastic market demand, the seller determines the product's order quantity and sales price to maximize its profit. In other words, this is a market dominated by product 
manufacturers, who have an advantage in information. The model is a static noncooperative game model, and each decision-maker can only make a decision once. There are two ways to describe the stochastic demand function: the additive form and the multiplicative form. In either case, demand includes a deterministic part $D(p)$ (a decreasing function of $p$ ) and a random variable $\delta$. In this paper, we use the multiplication form to describe the market demand, that is, $R D(p, \delta)=D(p) \delta$. For convenience, Table 1 shows the notation and definitions for the model.

Next, to make the newsboy model mathematically solvable (i.e., not deviating seriously from the actual situation), this paper proposes four hypotheses and explains the rationality of each.

$\mathrm{H}_{1}$ : the random variable $\delta_{3}$ is independent of $p_{3}$, and $E\left[\delta_{3}\right]=1$, so $E\left[R D_{3}\right]=D_{3}\left(p_{3}\right)$. The hypothesis shows that the overall trend of the seller's demand is determined by the product's price, but the real demand is controlled by a random variable $\delta_{3}$ that obeys a certain distribution.

$\mathrm{H}_{2}$ : the seller's decision variable $p_{3}$ changes only in the interval $\left[c_{3}, p^{\prime}\right]$, where $p^{\prime}$ is the maximum retail price asked by the sellers for the products. It is impossible for the seller to sell the product at a price lower than the purchase cost, so $p_{3} \geq c_{3}$. At the same time, to prevent product prices from getting out of control, the government often gives guidance prices and limits product prices to a reasonable range, so we assign an upper limit of $p_{3}$, and the maximum price is $p^{\prime}$.

$\mathrm{H}_{3}$ : the price elasticity $\theta_{3}$ of $D_{3}$ is a monotonic function of $p_{3}$, that is, $\partial \theta_{3} / \partial p_{3}>0$. According to the definition of price elasticity, it can be expressed as $\theta_{3}=\left(\left(\partial \theta_{3} / \partial p_{3}\right) /\left(D_{3} / p_{3}\right)\right)$. This hypothesis shows that an increase in seller's product price reduces the expected demand, making it easier to lose customers.

$\mathrm{H}_{4}: \delta_{3}$ is well-distributed within $\left[1-\varphi_{3}, 1+\varphi_{3}\right]$, where $\varphi_{3} \in[0,1]$. This hypothesis shows that the market demand of sellers is uniformly distributed in $\left[\left(1-\varphi_{3}\right) D_{3},\left(1+\varphi_{3}\right) D_{3}\right]$.

Based on these four assumptions and the decisionmaking analysis of the newsboy model, we construct the expected utility function of the retailer. The expected utility function is

$$
\left.U_{3}\left(p_{3}, q_{3}\right)=p_{3} E \delta_{3}\left[q_{3} \wedge D_{3} p_{3}\right) \delta_{3}\right]-c_{3} q_{3} .
$$

For a given marginal cost (manufacturer's price), the seller is faced with a newsboy pricing problem. Therefore, the expected utility function of the seller can be modified as follows:

$$
\begin{aligned}
U_{3}\left(p_{3}, q_{3}\right)= & p_{3}\left\{D_{3} \int_{0}^{D_{3} / q_{3}} t f_{\delta_{3}}(t) \mathrm{dt}+q_{3} \int_{D_{3} / q_{3}}^{\infty} f_{\delta_{3}}(t) \mathrm{dt}\right\} \\
& -c_{3} q_{3} .
\end{aligned}
$$

\subsubsection{Total Utility Function for Supplier-Manufacturer-Seller} Supply Chain. The utility functions for suppliers, manufacturers, and sellers are combined to construct the total utility function for a supplier-manufacturer-seller supply chain by analyzing the signal game between suppliers and manufacturers and the newsboy decision-making of sellers under the manufacturer's lead. We propose herein a group utility function as a total utility function. To ensure that all decision-makers (suppliers, manufacturers, and sellers) can measure the utility of each element in a given decision set, we set the range of individual utilities, which is the element utility value of suppliers, manufacturers, and sellers, to be between 0 and 1 (calculation standard is the ratio of the actual utility value to the possible maximum utility value). The range from 0 to 1 represents the utility level from low to high. The total utility function $V\left(a_{1}, p_{1}, b_{2}, q_{2}, p_{3}, q_{3}\right)$ is

$$
\begin{aligned}
V\left(a_{1}, p_{1}, b_{2}, q_{2}, p_{3}, q_{3}\right)= & \omega_{1} \cdot U_{1}+\omega_{2} \cdot U_{2}+\omega_{3} \cdot U_{3} \\
= & \omega_{1} \cdot\left(p_{1} \cdot q_{2}-\frac{1}{2} \mu^{-1} a_{1}^{\eta}+b_{2} \cdot \varepsilon\right) \\
& +\omega_{2} \cdot\left[q_{2} \cdot \eta+a_{1} \cdot \varepsilon b_{2}-b_{2}-p_{1} \cdot q_{2}-\left(\varepsilon-q_{2}\right)^{2}\right] \\
& +\omega_{3} \cdot p_{3}\left\{D_{3} \int_{0}^{D_{3} / q_{3}} t \cdot f_{\delta_{3}}(t) \mathrm{dt}+q_{3} \int_{D_{3} / q_{3}}^{\infty} f_{\delta_{3}}(t) \mathrm{dt}\right\}-\omega_{3} \cdot c_{3} q_{3}, \\
& \quad \text { s.t. } a_{1}, p_{1}, b_{2}, q_{2}, p_{3}, q_{3} \in[0,1],
\end{aligned}
$$

where $\omega_{1}, \omega_{2}$, and $\omega_{3}$ are the contribution weights of suppliers, manufacturers, and sellers, respectively, to the total utility of the supply chain. Note that $\omega_{1}+\omega_{2}+\omega_{3}=1$ and $\omega_{1}, \omega_{2}, \omega_{3} \in[0,1]$. 
TABle 1: Notation and definitions for the newsboy model.

\begin{tabular}{lc}
\hline Variable notation & Variable meaning \\
\hline$c_{3}$ & Seller's marginal cost of products \\
$p_{3}$ & Seller's product pricing \\
$q_{3}$ & Seller's order quantity \\
$D_{3}$ & Determination part of seller's product demand, which can also be expressed as $D_{3}\left(p_{3}\right)$ \\
$\theta_{3}$ & Price elasticity of seller's product demand \\
$\delta_{3}$ & Stochastic part of seller's product demand \\
$\varphi_{3}$ & Consumer demand coefficient for products; the larger the coefficient, the smaller the consumer demand \\
$f_{\delta_{3}}(t)$ & Density function of a random variable $\delta_{3}$ \\
$R D_{3}$ & Seller's demand function for products, where $R D_{3}=D_{3} \cdot \delta_{3}$ \\
$U_{3}\left(p_{3}, q_{3}\right)$ & Seller's expected utility function \\
\hline
\end{tabular}

\subsection{GA Optimization of Supply Chain Based on Game Decision-Making Model}

2.3.1. Design of Optimization by Genetic Algorithm. Based on the objective optimization function of a supply chain (i.e., the maximum total utility function), we use a GA to optimize a supply chain. A GA is a computational model based on biological evolution that simulates the evolutionary process of natural selection and the genetic mechanism to search for the optimal solution in an evolutionary process. Therefore, a GA is suitable for the supply-chain game and the optimization problem studied herein. The GA mathematically transforms the solution of the problem into a computer simulation process of chromosome and gene crossover and mutation in biological evolution and transforms the objective function of the problem into the fitness function as the search information in the GA. Based on a signal game and newsboy model, we set as a fitness function for the supply chain the total utility function of supplier-manufacturer-seller and use the GA to find the optimal solution for the supply chain's total utility. Figure 2 shows the basic procedure of a GA.

The implementation of the GA for supply-chain optimization includes determining coding schemes, establishing fitness functions, designing genetic operators, and selecting control parameters.

(1) Determine Coding Scheme. in the game decision-making model for a supply chain, the goal of suppliers, manufacturers, and sellers is to maximize their interests, which is affected by a variety of parameters in the game process. From the game results and the total utility function of the supply chain, we obtain six main optimization parameters, $a_{1}, p_{1}, b_{2}, q_{2}, p_{3}$, and $q_{3}$, which constitute the spatial parameters of the optimization problem for the objective function. Therefore, the game problem among members in the supply chain becomes an optimization problem for a multiparameter.

To optimize a supplier-manufacturer-seller supply chain, we select the GA coding scheme as the coding structure of multiparameter mapping. The basic idea is that the six optimization parameters are encoded to get the substring, and then, these substrings are connected into a complete chromosome. The range of each parameter is related to the actual order of magnitude of the problem, which belongs to the abstraction of the actual problem. In this paper, the GA based on the game decision-making model for supply chain uses 42-bit coding; each parameter has 7 bits.

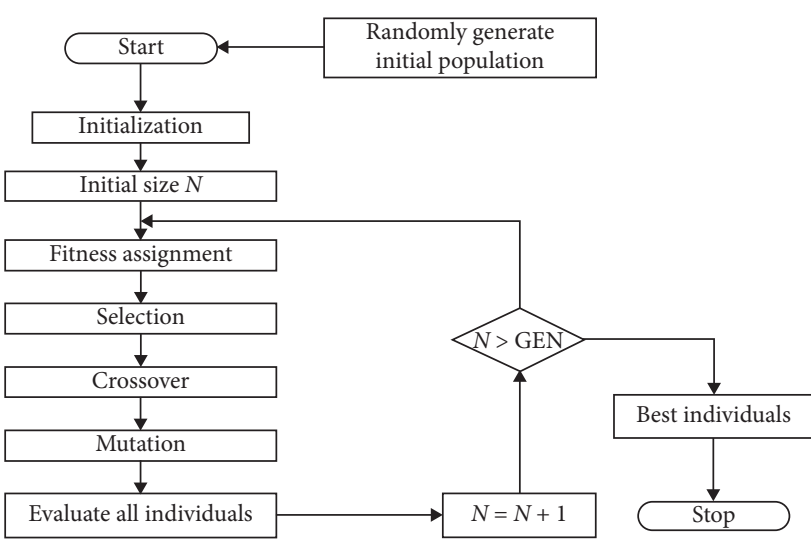

Figure 2: Basic flowchart of GA.

(2) Establishing the Fitness Function. fitness refers to the individual's ability to adapt to the environment. The fitness function in GAs is also called the evaluation function and is used to judge an individual's advantages and disadvantages in the group and evaluate according to the objective function of the problem. The GA uses the fitness function to evaluate the quality of an individual (solution) and as the basis for subsequent genetic operation. The design of a fitness function satisfies the following conditions: (i) single valued, continuous, nonnegative, and maximized; (ii) a whole consistency; (iii) less computation complexity; (iv) high universality. The design of the fitness function is mainly based on the objective function of maximizing the total utility function with the game relationship of members in the supply chain. In this paper, the objective function of the utility maximization for the supply chain is taken as the fitness function of the GA. The fitness function is

$$
F^{\prime}=V\left(a_{1}, p_{1}, b_{2}, q_{2}, p_{3}, q_{3}\right)=\omega_{1} U_{1}+\omega_{2} U_{2}+\omega_{3} U_{3} .
$$

In addition, to ensure that the fitness function is nonnegative, the following transformation is made:

$$
\begin{aligned}
F & =F^{\prime}, \\
F^{\prime} & >0, \\
F & =10^{-6}, \\
F^{\prime} & \leq 0 .
\end{aligned}
$$


(3) Designing Genetic Operators and Selecting Control Parameters.

(i) Design of genetic operators: the task of GA is to apply, according to their adaptability to the environment, certain operations to individuals in the initial population formed by the coding to do the optimization. The genetic operation mainly includes three basic genetic operators: selection operator, crossover operator, and mutation operator. The searching ability of the GA is mainly determined by the selection operator and the crossover operator, whereas the mutation operator ensures that the algorithm searches every solution in the problemsolution space so that the algorithm offers global optimization. According to the behavior strategy characteristics of suppliers, manufacturers, and sellers, the selection operator is determined by the fitness proportion method, the crossover operator is a single-point crossover operator, and the mutation operator is a basic bit mutation operator.

(ii) Control parameters: in establishing the structure of GAs, it is necessary to determine their control parameters. The main parameters include population size $N$, crossover probability $P_{x}$, and mutation probability $P_{m}$. The crossover probability and mutation probability are set to $P_{x}=0.6$ and $P_{m}=0.005$, the population size is set to $N=4$ to simplify the calculation, and the genetic evolution algebra is set to 100 .

The fitness function established in this paper has strong convergence and can optimize the supply chain. In the process of supply-chain optimization for specific examples, combined with the characteristics of a supplier-manufacturer-seller supply chain and based on the actual situation of a specific supply chain, the fixed parameters (control parameters) in the fitness function are assigned, and then, the optimal solution of the total utility of the supply chain and the six optimal parameters of the optimal utility are obtained by using the GA.

\subsubsection{Description of Optimization Genetic Algorithm Process.} The six optimization parameters of the group-selection strategy of members in the supply chain constitute the fitness-function parameters. To be easy to grasp, these parameters are set to be discrete, so this algorithm belongs to the combinatorial optimization problem. The optimization process of the algorithm is implemented in MATLAB 6.5 by using the GA toolbox. The optimization process is as follows:

Step 1: the group size $N=4$ is determined, and $N$ possible solutions $X_{i}(k)(1 \leq i \leq 4)$ are generated at random. Each possible solution is composed of six parameters.

Step 2: for each individual $X_{i}(k)$, the fitness $F\left(X_{i}(k)\right)$ is calculated by using the formula for the total utility function of the supply chain (see formulas (5) and (7)).
Step 3: according to selection rules in the roulette, the survival probability of each individual $X_{i}(k)$ is calculated. The selection operator $p_{i}(k)=\left(F\left(X_{i}(k)\right) /\right.$ $\left.\sum_{i=1}^{n}\left(F X_{i}(k)\right)\right)$, and a random selector is designed to generate the breeding individuals $X_{i}(k)$ by using a random method according to $p_{i}(k)$.

Step 4: two mating individuals $X_{1}(k)$ and $X_{2}(k)$ are selected and combined into two next-generation individuals $X_{1}(k+1)$ and $X_{2}(k+1)$ according to the rule of single-point crossover and basic position variation until $N$ next-generation individuals are formed.

Step 5: repeat steps 2-4 until the end condition of the program is met (reaching the end $K$ ).

\section{Simulation Example}

3.1. Example and Parameter Setting. This example assumes that a supply chain oriented by manufacturing firms consists of three members and one market, including supplier $\mathrm{A}$, manufacturer $\mathrm{B}$, seller $\mathrm{C}$, and target market $\mathrm{M}$, that is, $N=4$. Table 2 shows the relevant fixed parameters of the example. In addition, $D_{3}$ is a monotonically decreasing function of $p_{3}$, so the demand function of seller $\mathrm{C}$ for products affected by price in target market $M$ is expressed as $D_{3}=1-0.6 p_{3}$. The demand for final products in target market $M$ is evenly distributed in the interval $\left[\left(1-\varphi_{3}\right) D_{3},\left(1+\varphi_{3}\right) D_{3}\right]$. The random variable $\delta_{3}$ follows the distribution of the density function $f_{\delta_{3}}(t)$, which is expressed as

$$
f_{\delta_{3}}(t)= \begin{cases}1, & t \in\left[1-\varphi_{3}, 1+\varphi_{3}\right] . \\ 0, & \text { otherwise. }\end{cases}
$$

Based on these parameter settings, when combined with the actual situation, the range of optimization variables is set, as shown in Table 3.

Before the optimization operation uses the GA of the supply chain, we must input the fixed parameter values in the mode so that the algorithm can be used in the game optimization process between different agents in the supply chain. In a word, through the setting of the relevant fixed parameters (see Table 2) and the setting of the optimal parameter range (see Table 3), the GA of the supply-chain game model is iterated and runs many times in MATLAB6.5, producing the final optimal solution.

3.2. Operating Results and Analysis of Optimization. After 100 generations of genetic evolution, the optimal individual is (decimal representation) $x=0.8770 .9340 .3730 .0870 .253$ 0.560 and the optimal fitness is (decimal representation) $F=0.72976$. Figures 3 and 4 show the optimized emulation results.

The optimized results of the simulation (see Figures 3 and 4) show that, under the total optimal utility of the supply chain, the supplier's level of investment in advertising and the price level of raw materials and parts are higher, whereas the manufacturer's consulting investment level for intermediate products (raw materials and parts) and the level of the manufacturer's purchasing quantity for intermediate 
TABLE 2: Setting of relevant fixed parameters.

\begin{tabular}{lccc}
\hline Parameter name & Parameter notation & Parameter range & Example parameter value \\
\hline Perceived coefficient of supplier's advertising investment & $\mu$ & {$[0,1]$} & 0.8 \\
Supplier's quality type & $\eta$ & {$[0,1]$} & 0.7 \\
Manufacturer's demand type & $\varepsilon$ & {$[0,1]$} & 0.9 \\
Seller's marginal cost of products & $c_{3}$ & {$\left[0, p_{3}\right]$} & 0.3 \\
Consumer demand coefficient for products & $\varphi_{3}$ & {$[0,1]$} & 0.5 \\
Supplier's contribution weight for total utility & $\omega_{1}$ & {$[0,1]$} & 0.35 \\
Manufacturer's contribution weight for total utility & $\omega_{2}$ & {$[0,1]$} & 0.45 \\
Seller's contribution weight for total utility & $\omega_{3}$ & 0.2 \\
\hline
\end{tabular}

TABLE 3: Range of optimization parameters.

\begin{tabular}{lcc}
\hline Parameter name & Parameter notation & Parameter range \\
\hline Supplier's investment level in advertising & $a_{1}$ & {$[0,1]$} \\
Supplier's price level of raw materials and parts & $p_{1}$ & {$[0,1]$} \\
Manufacturer's consulting investment level for raw materials and parts & $b_{2}$ & {$[0,1]$} \\
Manufacturer's purchasing quantity for raw materials and parts & $q_{2}$ & {$[0,1]$} \\
Seller's order quantity & $q_{3}$ & {$[0,1]$} \\
Seller's pricing & $p_{3}$ & {$[0.3,1]$} \\
\hline
\end{tabular}

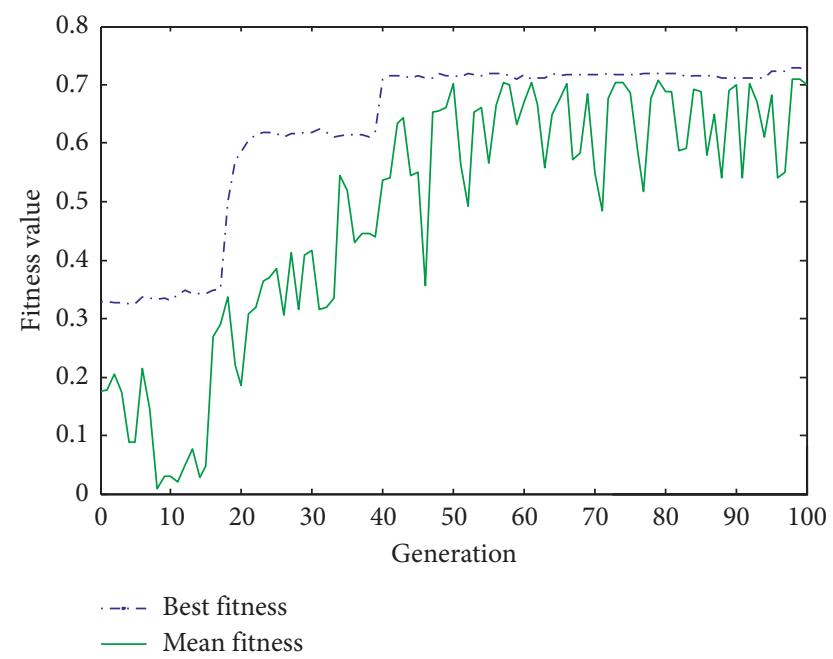

Figure 3: Trajectory of evolutionary process over 100 iterations.

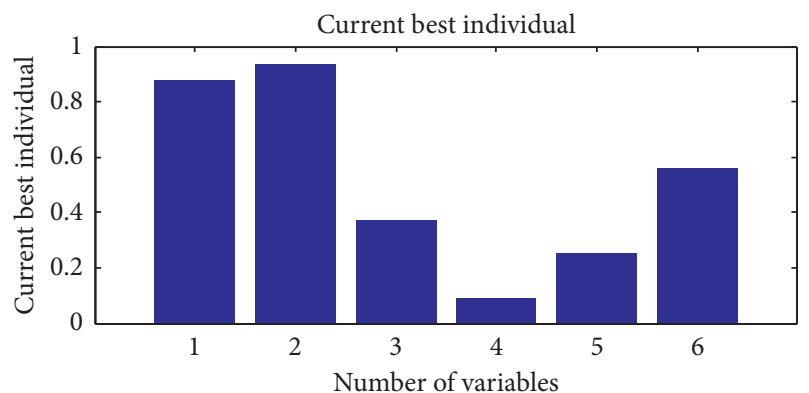

(a)

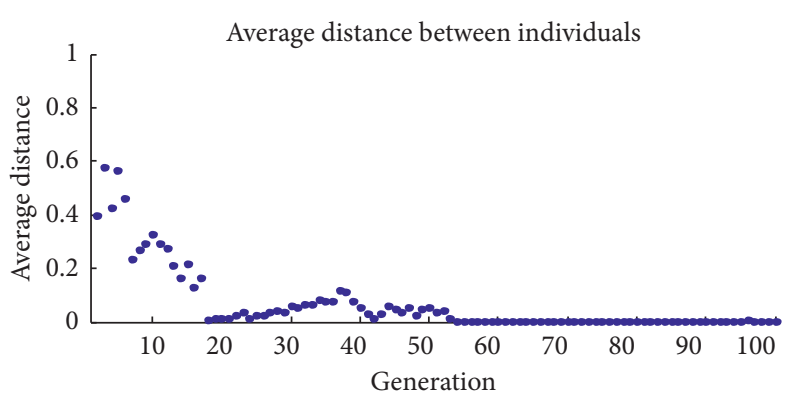

(b)

FIGURE 4: Variation of evolutionary individual optimal and evolutionary processes. 
products (raw materials and parts) are not high. The results show that the supplier should invest in more advertising to let manufacturers know their advantages. The results also show that manufacturers are willing to pay high prices for high-quality raw materials and parts, so suppliers should try to improve the quality of raw materials and parts rather than reduce prices. In addition, under the optimal solution, the seller's product order quantity is small, and the product pricing is at an intermediate level, which is indicative of relatively stable market demand for the product. Therefore, given a slight demand fluctuation (less demand risk), the seller can maintain a low level of product order quantity, thus reducing the seller's inventory management cost and reducing the product backlog.

\section{Conclusions}

Manufacturer-oriented supply-chain optimization is currently the emphasis of research worldwide, although the complex factors affecting the decision-making of supplychain businesses make the research more complicated. Making some basic assumptions, this paper studies the "supplier-manufacturer-seller" game decision-making model of a supply chain, which is based on a signal game and the newsboy model. We furthermore design a GA optimization method based on the game decision-making model of supply chains. The selection, crossover, mutation, and other operations in GA make this approach adaptable for all kinds of actors to the environment is gradually improved. Suppliers, manufacturers, and sellers constantly modify their behavior to act in a way that maximizes the total utility to the supply chain. In general, GA optimization based on the game decision-making model of supply chains provides a quantitative support tool for signal selection, transaction decisions, and for setting the pricing strategy of business members.

However, we only describe the implementation process for using a GA to optimize the supply chain based on the game decision-making model but do not conduct in-depth research on the theoretical aspects of GAs, such as proving algorithm convergence, estimating algorithm convergence speed, preventing premature mechanisms, or setting the crossover probability, mutation probability, and other genetic parameters. In other words, the algorithm proposed herein may be further optimized and is thus expected to be improved in future research.

\section{Data Availability}

The data used to support the findings of this study are available from the corresponding author upon request.

\section{Conflicts of Interest}

The authors declare that there are no conflicts of interest regarding the publication of this paper.

\section{Acknowledgments}

This work was supported by the Institute Guo Qiang, Tsinghua University (2019GQG1017), National Social
Science Fund of China (19ZDA329), and Education Department of Guangxi Government Foundation (2020KY05041).

\section{References}

[1] M. Christopher, "The agile supply chain," Industrial Marketing Management, vol. 29, no. 1, pp. 37-44, 2000.

[2] A. Burinskiene, "Pharma supply chain: efficiency modelling approach," Journal of System and Management Sciences, vol. 8, no. 2, pp. 65-73, 2018.

[3] M. Hossain and S. Ahmed, "A case study on safety assessment of construction project," Journal of Logistics, Informatics and Service Science, vol. 5, no. 2, pp. 68-83, 2018.

[4] A. A. Taleizadeh and M. Sherafati, "A three-level supply chain with warranty services, pricing and marketing decisions," Journal of Modelling in Management, vol. 14, no. 3, pp. 686-716, 2019.

[5] V. Kayvanfar, S. M. Moattar Husseini, B. Karimi, and M. S. Sajadieh, "A practical supply-demand hub in industrial clusters: a new perspective," Management Research Review, vol. 42, no. 1, pp. 68-101, 2019.

[6] J. Li, S. Wang, and T. C. E. Cheng, "Competition and cooperation in a single-retailer two-supplier supply chain with supply disruption," International Journal of Production Economics, vol. 124, no. 1, pp. 137-150, 2010.

[7] N. Moradinasab, M. R. Amin-Naseri, T. J. Behbahani, and H. Jafarzadeh, "Competition and cooperation between supply chains in multi-objective petroleum green supply chain: a game theoretic approach," Journal of Cleaner Production, vol. 170, pp. 818-841, 2018.

[8] L. V. Snyder and Z. M. Shen, "Supply chain contracts," Fundamentals of Supply Chain Theory, vol. 14, 2019.

[9] A. L. Awaga, W. Xu, L. Liu, and Y. Zhang, "Evolutionary game of green manufacturing mode of enterprises under the influence of government reward and punishment," Advances in Production Engineering \& Management, vol. 15, no. 4, pp. 416-430, 2020.

[10] A. Roy, S. S. Sana, and K. Chaudhuri, "Optimal replenishment order for uncertain demand in three layer supply chain," Economic Modelling, vol. 29, no. 6, pp. 2274-2282, 2012.

[11] M. Pakseresht, B. Shirazi, I. Mahdavi, and N. Mahdavi-Amiri, "Toward sustainable optimization with stackelberg game between green product family and downstream supply chain," Sustainable Production and Consumption, vol. 23, pp. 198$211,2020$.

[12] K. Matsui, "Optimal bargaining timing of a wholesale price for a manufacturer with a retailer in a dual-channel supply chain," European Journal of Operational Research, vol. 287, no. 1, pp. 225-236, 2020.

[13] L. Shao, J. K. Ryan, and D. Sun, "Responsible sourcing under asymmetric information: price signaling versus supplier disclosure," Decision Sciences, vol. 51, no. 5, pp. 1082-1109, 2020.

[14] P. Radhakrishnan, M. R. Gopalan, and N. Jeyanthi, "Design of Genetic Algorithm based supply chain inventory optimization with lead time," International Journal of Computer Science and Network Security, vol. 10, pp. 238-246, 2010.

[15] D. Istokovic, M. Perinic, M. Vlatkovic, and M. Brezocnik, "Minimizing total production cost in a hybrid flow shop: a simulation-optimization approach," International Journal of Simulation Modelling, vol. 19, no. 4, pp. 559-570, 2020.

[16] M. V. Pirnagh, H. Davari-Ardakani, and S. H. R. Pasandideh, "Designing a Bi-objective closed-loop supply chain problem 
with shortage and all unit discount: "nondominated sorting genetic algorithm II" and "Multi-Objective particle swarm optimization"” Journal of Advanced Manufacturing Systems, vol. 19, no. 4, pp. 701-736, 2020.

[17] D. L. Shi, B. B. Zhang, and Y. Li, "A multi-objective flexible job-shop scheduling model based on fuzzy theory and immune genetic algorithm," International Journal of Simulation Modelling, vol. 19, no. 1, pp. 123-133, 2020.

[18] M. K. Amjad, S. I. Butt, N. Anjum, I. A. Chaudhry, Z. Faping, and M. Khan, "A layered genetic algorithm with iterative diversification for optimization of flexible job shop scheduling problems," Advances in Production Engineering \& Management, vol. 15, no. 4, pp. 377-389, 2020.

[19] L. L. Hou and W. H. Qiu, "Supply chain demand information sharing mechanism based on signaling game," Control \& Decision, vol. 12, pp. 1421-1424, 2007.

[20] M. Ota, S. Srinivasan, and C. D. Nandakumar, "Optimal order quantity by maximising expected utility for the newsboy model," International journal of procurement management, vol. 12, pp. 410-424, 2019.

[21] B. F. Zhang, D. S. Wu, L. Liang et al., "Supply chain loss averse newsboy model with capital constraint," IEEE Transactions on Systems Man \& Cybernetics Systems, vol. 46, no. 5, pp. 646658, 2015.

[22] D. Du, B. Chen, and D. Xu, "Quantifying the efficiency of price-only contracts in push supply chains over demand distributions of known supports," Omega, vol. 42, no. 1, pp. 98-108, 2014.

[23] W. Zhang and J. K. Zhang, "Profit and the balance of risks in supply chain management research based on the newsboy model," Value Engineering, vol. 37, no. 3, pp. 106-109, 2018. 